\title{
Nonpharmacological interventions to treat physical frailty and sarcopenia in older patients: a systematic overview - the SENATOR Project ONTOP Series
}

Clinical Interventions in Aging

24 April 2017

Number of times this article has been viewed

Isabel Lozano-Montoya ${ }^{1, *}$

Andrea Correa-Pérez ${ }^{1, *}$

losief Abraha ${ }^{2}$

Roy L Soiza ${ }^{3}$

Antonio Cherubini ${ }^{2}$

Denis O'Mahony ${ }^{4}$

Alfonso J Cruz-Jentoft'

'Servicio de Geriatría, Hospital

Universitario Ramón y Cajal

(IRYCIS), Madrid, Spain; ${ }^{2}$ Geriatrics

and Geriatric Emergency Care, Italian National Research Center on Aging (IRCCS-INRCA), Ancona, Italy; ${ }^{3}$ Department of Medicine

for the Elderly, National Health Service Grampian, Aberdeen, UK; ${ }^{4}$ Department of Medicine, University College Cork, Cork, Ireland

*These authors contributed equally to this work
Correspondence: Isabel Lozano-Montoya Hospital Central de la Cruz Roja San José y Santa Adela, Avenida Reina Victoria 22-26, 28003, Madrid, Spain Email ilozanom@salud.madrid.org

Andrea Correa-Pérez Servicio de Geriatría, Hospital Universitario Ramón y Cajal (IRYCIS) Crta. Colmenar Viejo Km 9.I, 28034, Madrid, Spain

Email andrea.correa@salud.madrid.org
Background: Physical frailty (PF) and sarcopenia are predictors of negative health outcomes such as falls, disability, hospitalization, and death. Some systematic reviews (SRs) have been published on different nonpharmacological treatments of frailty and sarcopenia using heterogeneous definitions of them.

Objective: To critically appraise the evidence from SRs of the primary studies on nonpharmacological interventions to treat PF (defined by Fried's frailty phenotype) and sarcopenia (defined by the EWGSOP) in older patients.

Design: Overview of SRs and meta-analysis of comparative studies.

Data sources: PubMed, Cochrane Database of Systematic Reviews, EMBASE, and CINAHL were searched in October 2015.

Eligibility criteria for selecting studies: SRs that included at least one comparative study evaluating any nonpharmacological intervention to treat PF or sarcopenia in older patients in any health care setting. Any primary study described in these SRs with experimental design was included

Data extraction and management: Two reviewers independently screened titles, abstracts, and full-texts of articles. Quality assessment was carried out by using criteria from the Cochrane Collaboration and the GRADE working group.

Results: Ten SRs with 5 primary studies satisfied the inclusion criteria. The most frequent interventions in the included studies were physical exercise (4) and nutritional supplementation (2). Muscle strength (MS; except for one study in a frail population) and physical performance (PP; except for another study in a frail population) improved with exercise and amino acid supplementation in frail and sarcopenic old adults. Falls and activities of daily living were assessed in two studies with opposite results. The overall quality of the evidence was low.

Conclusion: This overview of SRs highlights the importance of exercise interventions with or without nutritional supplementation to improve the PP in community-dwelling patients aged $>65$ years with PF and sarcopenia. MS improved with multidisciplinary treatment and exercise interventions in this population.

Keywords: review, exercise, nutrition, older adults

\section{Introduction}

Frailty can be seen as the weakening of health (defined as the resilience or capacity to cope and to maintain and restore one's integrity, equilibrium, and sense of well-being in three domains: physical, mental, and social). ${ }^{1,2}$ Clinically, it has been defined as 
a "multidimensional syndrome characterized by decreased reserve and diminished resistance to stressors." "It is considered a treatable condition that may be reversible. ${ }^{3}$ Although no definition is universally accepted, two predominant models have emerged to understand frailty:1,4 Fried's phenotypical approach to physical frailty $(\mathrm{PF})^{5}$ and Rockwood's operationalization of a model of accumulation of deficits. ${ }^{6}$ In the current scientific literature, Fried's phenotype is the most widely used method to define, ${ }^{7}$ where PF is defined as a multifactorial syndrome characterized by diminished strength, endurance, and reduced physiologic function that increases an individual's vulnerability to develop increased dependency and/or death. ${ }^{2}$ Rockwood's Index considers not only the physical aspects of frailty but also other domains such as psychological and social domains. A major difference is that the latter model may include any degree of disability as a vulnerability factor (ie, present disability increases frailty), whereas the former model considers frailty as a vulnerability to disability, as the previous stage to disability. These two approaches should be considered as complementary and not mutually exclusive. ${ }^{8}$

Sarcopenia is the presence of low muscle mass plus low muscle function (muscle strength [MS] or physical performance [PP]) associated with aging. ${ }^{9}$ Recent research has highlighted sarcopenia as the biological substrate of PF, ${ }^{10}$ skeletal muscle decline being one of its key components. Recent research confirms that Fried's frailty phenotype and the European Working Group on Sarcopenia in Older People (EWGSOP)-defined sarcopenia are strongly correlated. ${ }^{11}$ Both the entities are the predictors of negative health outcomes such as falls, disability, hospitalization, and death. ${ }^{12-17}$ Interventions are necessary to reverse the frailty status and to treat sarcopenia in order to avoid further negative health outcomes. ${ }^{3}$

Some systematic reviews (SRs) have been published in recent years on different nonpharmacological treatments of frailty and sarcopenia (physical exercise and nutritional supplementation being the usual components). However, the current definitions of frailty and sarcopenia that are in use are heterogeneous, and different inclusion criteria have been used. Therefore, the aims of this overview of reviews were as follows: 1) to identify all published SRs on nonpharmacological interventions of PF (defined by Fried's frailty phenotype) and sarcopenia (defined by the EWGSOP), 2) to identify and critically appraise the primary studies included in these SRs by using the Optimal evidence-based Non-drug Therapies in Older People (ONTOP) methodology, ${ }^{18}$ and 3 ) to critically summarize the evidence and emphasize its limitations in order to suggest research priorities for future studies.

\section{Methods}

This paper is part of the ONTOP project, a work package of a European Union-funded FP 7 research named SENATOR (Software ENgine for the Assessment \& Optimization of drug and non-drug Therapy in Older persons [www.senatorproject.eu]); detailed methodology of ONTOP has been published previously. ${ }^{18}$ Briefly, the ONTOP objective is to develop a literature overview of reviews of nonpharmacological treatments of 10 prevalent medical conditions affecting older people. The present paper reports evidence-based interventions for the treatment of sarcopenia and frailty in older people.

The ONTOP Evidence Group defined the clinical questions according to the Grading of Recommendations Assessment, Development and Evaluation (GRADE) ${ }^{19}$ method. A Delphi process using a group of independent international experts in Geriatric Medicine helped to establish the critical outcomes that should be considered for selecting papers and reporting results in this review (Table 1). Most critical outcomes included measures of muscle function, and some of them were compound variables. The expert group did not consider muscle mass as a critical outcome. Table 1 also lists the methods that were acceptable to assess each variable, following the EWGSOP recommendations.

Table I Delphi-defined critical outcomes for studies on interventions on physical frailty and sarcopenia and assessment methods for each outcome

\begin{tabular}{ll}
\hline Critical outcomes & Assessment methods \\
\hline Muscle strength & Handgrip strength \\
& Knee flexion/extension \\
& Peak expiratory flow \\
Physical performance & Short Physical Performance Battery \\
& Usual gait speed \\
& Timed Up and Go Test \\
& Stair climb power test \\
Muscle function: & Handgrip strength \\
strength and performance & Knee flexion/extension \\
& Peak expiratory flow \\
& + physical performance assessment \\
Muscle mass and & Bioimpedance analysis \\
muscle function & Dual energy X-ray absorptiometry \\
& Computer tomography \\
& Magnetic resonance imaging \\
& Total or partial body potassium per \\
& fat-free soft tissue \\
Falls & Anthropometric measures \\
\hline
\end{tabular}

Note: Data from Cruz-Jentoft. ${ }^{9}$ 


\section{Search strategy and selection of SRs}

Search strategies were launched in October 2015 in the following databases: Cochrane Database of Systematic Reviews, PubMed, EMBASE and CINAHL (Supplementary material 1). Montori's highly specific strategy was used for PubMed database. ${ }^{20}$

Two criteria were considered for further evaluation of any published abstract: 1) a paper defined as SR or meta-analysis and 2) the use of any nonpharmacological intervention for PF (defined by Fried's phenotype, either original or adapted) or sarcopenia (defined by the EWGSOP). ${ }^{9}$ Other records such as guidelines, conference proceedings, and program abstracts were excluded.

Later, full-texts of all relevant abstracts were obtained and screened to identify SRs of interest based on 1) the use of at least one medical literature database; 2) the inclusion of at least one primary study; 3 ) the use of at least one nonpharmacological intervention to treat $\mathrm{PF}$ or sarcopenia; and 4) the mean age of the subjects was $>65$ years. SRs written in English, Italian, Portuguese, or Spanish were considered.

\section{Inclusion and exclusion criteria for primary studies}

The included SRs were examined to identify any experimental comparative study, either randomized or nonrandomized, that investigated any nonpharmacological intervention to treat PF or sarcopenia in older patients.

Primary studies were excluded if they were observational studies or before-after studies with historical controls. Studies were also excluded when the mean age of subjects was $<65$ years, when frailty was assessed by using methods other than Fried's criteria, and when sarcopenia was not defined by the EWGSOP criteria. Trials with mixed frail and prefrail subjects were also excluded. Studies using conditions to define the population (eg, diabetes, COPD, and cancer) or using special populations (eg, athletes) were also excluded, as well as those exclusively considering patients admitted to intensive care or palliative care units. Only nutritional interventions that considered macronutrients were included; those using individual vitamins or micronutrients were excluded, as they were considered pharmacological interventions. Trials that did not assess any critical outcome (Table 1) were also excluded.

\section{Data extraction and management}

Results from primary studies were transferred onto data extraction forms. Information collected included trial and patient characteristics, intervention and comparator components as well as outcome measures. Two reviewers independently screened titles, abstracts, and full-texts of articles. Disagreement was resolved by discussion and, when needed, by a third senior reviewer.

\section{Risk of bias assessment}

Assessment of bias in the included primary studies was carried out by using criteria from the Cochrane Collaboration. ${ }^{21}$ Domains assessed were random sequence generation, allocation concealment, blinding of participants and personnel, blinding of outcome assessment, incomplete outcome data, selective reporting, and other potential biases such as differences in baseline conditions. Overall risk of bias was graded by including each study in one of three categories: low risk, high risk, and unclear risk. Two reviewers independently assessed the risk of bias of individual studies, and any differences in quality assessment results were resolved through consensus.

\section{Issues on the unit of analysis}

Subjects were treated as the unit of analysis in all primary studies included in this review.

\section{Data synthesis and analysis}

The results were presented in a narrative way with the information provided by the included studies. Nonpharmacological interventions varied widely across studies, and therefore, meta-analysis was not feasible.

\section{Grading the quality of evidence}

The quality of evidence was assessed with GRADE (Grading of Recommendations, Assessment, Development and Evaluation) methodology. ${ }^{19}$ GRADE assessment considers the risk of bias, consistency of results across the available studies, precision of the results, directness, and likelihood of publication bias, dose-response, and strength of the association, as well as plausible confounders that may have influence on the effect of the intervention. The quality of the evidence was categorized as high, moderate, low, or very low based on the authors' judgments for the critical outcomes.

\section{Results}

\section{SRs}

This search identified 9,277 abstracts after removing duplicates (Figure 1). Among the 130 reviews identified for fulltext evaluation, 10 were included (Table 2) and 120 were excluded, the main reason being that frailty and sarcopenia 


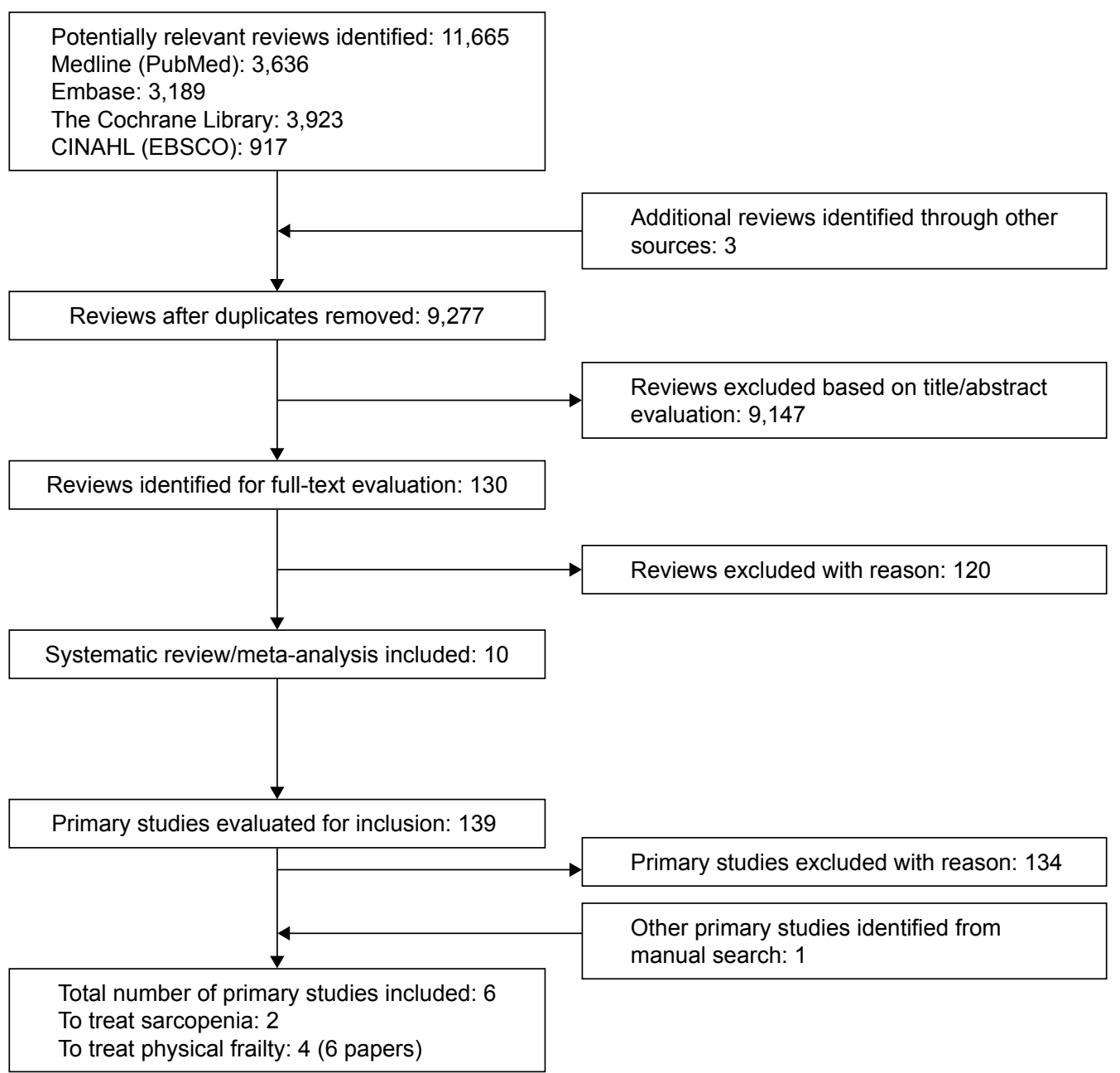

Figure I Screening process of the study.

were not defined using Fried's or EWGSOP criteria. The publication year of the SR included ranged from 1979 to 2015. These reviews were heterogeneous, encompassing nonpharmacological interventions such as nutritional supplementation and physical exercise for the treatment of PF and sarcopenia (Table 3).

\section{Primary studies}

Overall, the 10 SRs $^{22-31}$ yielded 140 primary studies, of which $7^{32-38}$ satisfied the inclusion criteria, but three of these presented the results of the same study. An additional relevant study was included after manual search ${ }^{39}$ (Table 4). The six primary studies finally included are listed in Table 5 . Table 6 summarizes the risks of bias in each study, which was mostly low due to the nature of the interventions except for performance bias.

\section{Sarcopenia}

Five out of $10 \mathrm{SRs}^{22-26}$ included sarcopenic populations. From these SRs, only one primary study (Kim et al) ${ }^{32}$ satisfied the inclusion criteria. In most cases, subjects were not defined by having sarcopenia, but by a range of other conditions, and in many cases, healthy subjects were included (Supplementary material 2). In addition, one relevant study was found after manual search. ${ }^{39}$

Evidence of exercise and amino acid supplementation (AAS) to treat sarcopenia in community-dwelling older people

One randomized controlled trial (RCT) ${ }^{32}$ evaluated four interventions: a multicomponent exercise program (MCEP), AAS, MCEP with AAS, and health education (HE) in 155 Japanese sarcopenic community-dwelling women. PP and MS were the outcome measures. After the 3-month intervention, MS assessed by knee extension improved only with the combination of MCEP and AAS (strength increased by 7\%) compared with HE (12.3\% strength loss, $P=0.02)$. PP assessed by $5-\mathrm{m}$ usual gait speed improved in MCEP $(+0.19 \mathrm{~m} / \mathrm{s})$ and MCEP + AAS groups $(+0.16 \mathrm{~m} / \mathrm{s})$ compared with HE $(+0.03 \mathrm{~m} / \mathrm{s}, P=0.0017)$. The authors of this trial concluded 
Table 2 Systematic reviews included

\begin{tabular}{|c|c|c|c|c|c|c|}
\hline $\begin{array}{l}\text { SR } \\
\text { included }\end{array}$ & Aim & $\begin{array}{l}\text { Population } \\
\text { age (years) }\end{array}$ & $\begin{array}{l}\text { Search } \\
\text { strategy date }\end{array}$ & Intervention & Outcome & $\begin{array}{l}\text { Primary } \\
\text { studies } \\
\text { selected }\end{array}$ \\
\hline \multicolumn{7}{|l|}{ Sarcopenia } \\
\hline $\begin{array}{l}\text { Cadore } \\
\text { et } \mathrm{al}^{22}\end{array}$ & $\begin{array}{l}\text { To recommend training supervised } \\
\text { exercise programs to improve muscle } \\
\text { strength, gait ability and fall risk }\end{array}$ & $>70$ & $1990-2012$ & $\begin{array}{l}\text { RT, ET, BT, BWRT, MCEP, TAI, } \\
\text { FT, COOT, SUP }\end{array}$ & MS, PP, falls & $\begin{array}{l}\text { I out } \\
\text { of } 20\end{array}$ \\
\hline $\begin{array}{l}\text { Cruz-Jentoft } \\
\text { et } \mathrm{al}^{23}\end{array}$ & $\begin{array}{l}\text { To review the effect of nutrition and } \\
\text { exercise interventions on muscle } \\
\text { function }\end{array}$ & $>50$ & $2000-2013$ & $\begin{array}{l}\text { RT, PA, multipurpose E, Prot, } \\
\text { EAA, HMB, fatty acids, ES }\end{array}$ & MS, PP & $\begin{array}{l}\text { I out } \\
\text { of } 19\end{array}$ \\
\hline Finger et $\mathrm{a}^{24}$ & $\begin{array}{l}\text { To summarize whether protein } \\
\text { supplementation could optimize } \\
\text { the effects of resistance training on } \\
\text { muscle strength }\end{array}$ & $>60$ & $\begin{array}{l}\text { Up to } \\
\text { January } 2014\end{array}$ & $\begin{array}{l}\text { RT + Prot (or modified diet with } \\
\text { increased protein content) vs RT } \\
\text { vs } R T+\text { with non-Prot placebo } \\
\text { supplementation }\end{array}$ & MS & $\begin{array}{l}\text { I out } \\
\text { of } 9\end{array}$ \\
\hline Komar et $\mathrm{a}^{25}$ & $\begin{array}{l}\text { To synthesize the literature relating } \\
\text { to leucine supplementation on muscle } \\
\text { strength }\end{array}$ & $>65$ & $\begin{array}{l}\text { Up to } \\
\text { February } 2014\end{array}$ & $\begin{array}{l}\text { Supplementation with Leu (at least } \\
2 \mathrm{~g} / \text { day) }\end{array}$ & MS & $\begin{array}{l}\text { I out } \\
\text { of } 16\end{array}$ \\
\hline $\begin{array}{l}\text { Malafarina } \\
\text { et } \mathrm{al}^{26}\end{array}$ & $\begin{array}{l}\text { To analyze the effects of } \\
\text { supplementation on muscle function }\end{array}$ & $>65$ & $199 \mid-2012$ & $\begin{array}{l}\text { Nutritional supplementation (AAS/ } \\
\text { ALA/EAA/HMB/Leu/Prot) } \pm \mathrm{E} \\
\text { ( } \geq 8 \text { weeks) }\end{array}$ & MS, PP & $\begin{array}{l}\text { I out } \\
\text { of } 17\end{array}$ \\
\hline \multicolumn{7}{|c|}{ Physical frailty } \\
\hline $\begin{array}{l}\text { Gine-Garriga } \\
\text { et } \mathrm{al}^{27}\end{array}$ & $\begin{array}{l}\text { To examine the effectiveness } \\
\text { of combined diet and exercise } \\
\text { interventions to improve physical } \\
\text { function }\end{array}$ & $\geq 65$ & April 2013 & $\begin{array}{l}\text { Diet interventions (based } \\
\text { on dietary modification) } \pm \mathrm{E} \\
\text { (RT/ST/STR/FT/BT) }\end{array}$ & MS, PP & $\begin{array}{l}\text { I out } \\
\text { of } 19\end{array}$ \\
\hline $\begin{array}{l}\text { de Labra } \\
\text { et } \mathrm{a}^{28}\end{array}$ & $\begin{array}{l}\text { To investigate the benefits of } \\
\text { exercise programs }\end{array}$ & $\begin{array}{l}\text { Not stated } \\
\text { (older adults) }\end{array}$ & $2003-2015$ & $\begin{array}{l}\text { RT, functional walking, MCEP, } \\
\text { BWRT, BT }\end{array}$ & $\begin{array}{l}M S, P P, \\
A D L, \text { falls }\end{array}$ & $\begin{array}{l}3 \text { out } \\
\text { of } 9\end{array}$ \\
\hline $\mathrm{Orr}^{29}$ & $\begin{array}{l}\text { To review the effect of whole body } \\
\text { vibration exposure on functional } \\
\text { mobility }\end{array}$ & $\geq 45$ & $\begin{array}{l}\text { Up to } \\
\text { October } 2014\end{array}$ & WBV, WBVE & PP & $\begin{array}{l}\text { I out } \\
\text { of } 20\end{array}$ \\
\hline $\begin{array}{l}\text { Plummer } \\
\text { et } \mathrm{al}^{30}\end{array}$ & $\begin{array}{l}\text { To compare any physical exercise } \\
\text { intervention to a control group on } \\
\text { dual-task interference during walking }\end{array}$ & $\geq 60$ & $\begin{array}{l}\text { Up to } \\
\text { September } 2014\end{array}$ & Dual-task interventions & PP & $\begin{array}{l}\text { I out } \\
\text { of } 2 \text { I }\end{array}$ \\
\hline $\begin{array}{l}\text { Zanotto } \\
\text { et } \mathrm{a}^{31}\end{array}$ & $\begin{array}{l}\text { To summarize how exercise affects } \\
\text { dual-task performance }\end{array}$ & $>59$ & $\begin{array}{l}\text { Up to } \\
\text { October } 2013\end{array}$ & Dual-task interventions, E, BT, TAI & PP & $\begin{array}{l}\text { I out } \\
\text { of } 17\end{array}$ \\
\hline
\end{tabular}

Abbreviations: AAS, amino acid supplement; ADL, activities daily living; ALA, alpha-linoleic acid supplement; BT, balance training; BWRT, body weight resistance training; COOT, coordination training; E, exercise; EAA, essential amino acid supplementation; ES, electrical stimulation; ET, endurance training; F, falls; FT, flexibility training; HMB, beta-hydroxy-beta-methylbutyrate supplement; Leu, leucin supplement; MCEP, multicomponent exercise program; MS, muscle strength; PA, physical activity; PP, physical performance; Prot, protein supplement; PRT, progressive resistance training; RT, resistance training; SR, systematic review; ST, strength training; STR, stretching; SUP, supplementation; TAl, Tai-Chi exercise; WBV, whole body vibration; WBVE, whole body vibration plus exercise.

that exercise and nutrition may be necessary to reverse the effects of sarcopenia in community-dwelling older women, but research on larger populations and also in males is needed to confirm these results.

Table 3 Nonpharmacologic interventions to treat physical frailty and sarcopenia with systematic reviews

\section{Sarcopenia}

Exercise

Amino acid supplementation

Exercise and amino acid supplementation

Health education

Physical frailty

Exercise

Nutritional supplementation

Exercise and nutritional supplementation

Multidisciplinary interventions
A second $\mathrm{RCT}^{39}$ evaluated the effects of exercise (resistance training; RT) in combination with AAS (collagen peptides) versus exercise with placebo during 3 months in 53 older community-dwelling sarcopenic men. Knee extension strength was used as the outcome measure. MS improved significantly in both the groups after 12 weeks, the effect being higher in the collagen peptide group $(+13.82 \%)$ than in the placebo group $(+5.3 \%, P<0.05)$. Authors suggested that these results might be due to the intensive training designed to induce muscular hypertrophy and the collagen effects on increasing muscle mass.

We did not poll these studies due to differences between participants and interventions used. In both the studies, blinding of participants was not possible due to the nature of the intervention. Methodological issues are synthesized 
Table 4 Distribution of primary studies in systematic reviews

\begin{tabular}{|c|c|c|c|c|c|c|c|c|}
\hline \multirow{4}{*}{$\begin{array}{l}\text { Systematic } \\
\text { reviews (10) }\end{array}$} & \multicolumn{8}{|c|}{ Primary studies (6) } \\
\hline & \multicolumn{2}{|c|}{ Sarcopenia (EWGSOP) } & \multicolumn{6}{|c|}{ Physical frailty (Fried's criteria) } \\
\hline & \multirow[t]{2}{*}{ Kim et $\mathbf{a l}^{32}$} & \multirow[t]{2}{*}{ Zdzieblik et al $^{39}$} & \multicolumn{3}{|c|}{ The Frailty Intervention Trial } & \multirow{2}{*}{$\begin{array}{l}\text { Cadore } \\
\text { et } \mathrm{al}^{36}\end{array}$} & \multirow{2}{*}{$\begin{array}{l}\text { Zhang } \\
\text { et } \mathbf{a l}^{37}\end{array}$} & \multirow{2}{*}{$\begin{array}{l}\text { Kim } \\
\text { et } \mathrm{al}^{38}\end{array}$} \\
\hline & & & Fairhall et $\mathrm{al}^{33}$ & Cameron et $\mathrm{al}^{34}$ & Fairhall et al ${ }^{35}$ & & & \\
\hline Cadore et a ${ }^{22}$ & $x$ & & & & & & & \\
\hline Malafarina et $\mathrm{a}^{26}$ & $\mathrm{X}$ & & & & & & & \\
\hline Cruz-Jentoft et a ${ }^{23}$ & $\mathrm{x}$ & & & & & & & \\
\hline Komar et $\mathrm{al}^{25}$ & $\mathrm{X}$ & & & & & & & \\
\hline Finger et $\mathrm{a}^{24}$ & $\mathrm{x}$ & & & & & & & \\
\hline Manual search & & $\mathrm{x}$ & & & & & & \\
\hline Gine-Garriga et al ${ }^{27}$ & & & $\mathrm{X}$ & $\mathrm{X}$ & & & & \\
\hline Zanotto et $\mathrm{al}^{31}$ & & & & & & $\mathrm{x}$ & & \\
\hline de Labra et $\mathrm{al}^{28}$ & & & & & $\mathrm{x}$ & $\mathrm{X}$ & & $\mathrm{x}$ \\
\hline Orr ${ }^{29}$ & & & & & & & $\mathrm{X}$ & \\
\hline Plummer et $\mathrm{al}^{30}$ & & & & & & $x$ & & \\
\hline
\end{tabular}

in Table 6. According to GRADE assessment, the quality or certainty of the evidence has been assessed as very low (Table 7) for the critical outcomes.

\section{PF}

Five out of $10 \mathrm{SRs}^{27-31}$ included physically frail populations. From these SRs, $4 \mathrm{RCTs}^{33-38}$ (described in 6 articles) were included; three articles ${ }^{33-35}$ described different aspects of the same study (the Frailty Intervention Trial - FIT), so that they are reported together here. Again, the main reason of exclusion was the use of varied nonstandard definitions of frailty (Supplementary material 3).

The number of patients included in these trials ranged from 32 to 241. All trials included participants over 70 years old, except one study performed in nursing homes, that included patients aged over 85 years. ${ }^{36}$ One trial included only women. ${ }^{38}$ The study characteristics are described in Table 5. In general, risk of bias was low, except for blinding of participants (Table 6).

\section{Efficacy}

This study considered that data of these studies could not be combined due to differences between the nonpharmacological interventions used.

\section{Evidence on multidisciplinary interventions in} physically frail community-dwelling older people A single study, The Frail Intervention Trial (FIT) $)^{40-42}$ evaluated the effects of an individualized multidisciplinary intervention versus usual care in 241 physically frail community-dwelling older people. The assessed outcomes of interest were MS, PP, falls and activities of daily living (ADL). After 12 months, there was a reduction in MS, assessed by knee extension strength, in both the groups: $-16.41 \%$ in the intervention group versus $-25.8 \%$ in the control group. This reduction was lower in the intervention group than the control group (between-group difference $1.84 \mathrm{~kg}, 95 \%$ confidence interval [CI] 0.17-3.51, $P=0.03$ ). PP, assessed by Short Physical Performance Battery (SPPB), just increased in the intervention group: +0.68 points versus -1.05 points in the control group (between-group difference at 12 months is 1.58 points, $95 \%$ CI 1.02-2.14, $P \leq 0.001)$. There was an increment in $4-\mathrm{m}$ walk test of $+0.07 \mathrm{~m} / \mathrm{s}$ in the intervention group compared with no changes in the control group (between-group difference at 12 months $0.06 \mathrm{~m} / \mathrm{s}, 95 \%$ CI $0.01-0.10, P=0.02$ ). MS, assessed by handgrip, was higher in the control group: $+0.93 \mathrm{~kg}$ in the intervention group versus $+1.88 \mathrm{~kg}$ control group although no significant differences were found between groups $(1.18 \mathrm{~kg}$, $95 \% \mathrm{CI}-013$ to $2.49, P=0.08)$. In addition, no significant differences were found in ADL, assessed by Barthel Index (BI) between groups after 12-month intervention ( 0.67 points, $95 \% \mathrm{CI}-4.23$ to $5.56, P=0.79)$. BI was higher in the control group than the intervention group (6.14 vs 5.56). There was no effect of the intervention on the rate of falls that was also similar in the intervention group (183 falls, 1.54 falls per person, standard deviation [SD] 2.58) and the control group (178 falls, 1.50 falls per person, SD 2.39) with an incidence rate ratio of 1.12 (95\% $\mathrm{CI} 0.78-1.63, P=0.53)$.

The risk of bias according to methodological issues was low except for performance and detection bias (Table 6). The quality or certainty of the evidence has been assessed as low (Table 8A) for the critical outcomes.

\section{Evidence on vibration exercise in physically frail community-dwelling older people}

A pilot $\mathrm{RCT}^{37}$ assessed the efficacy of whole-body vibration exercise (WBVE) versus usual care that included different 


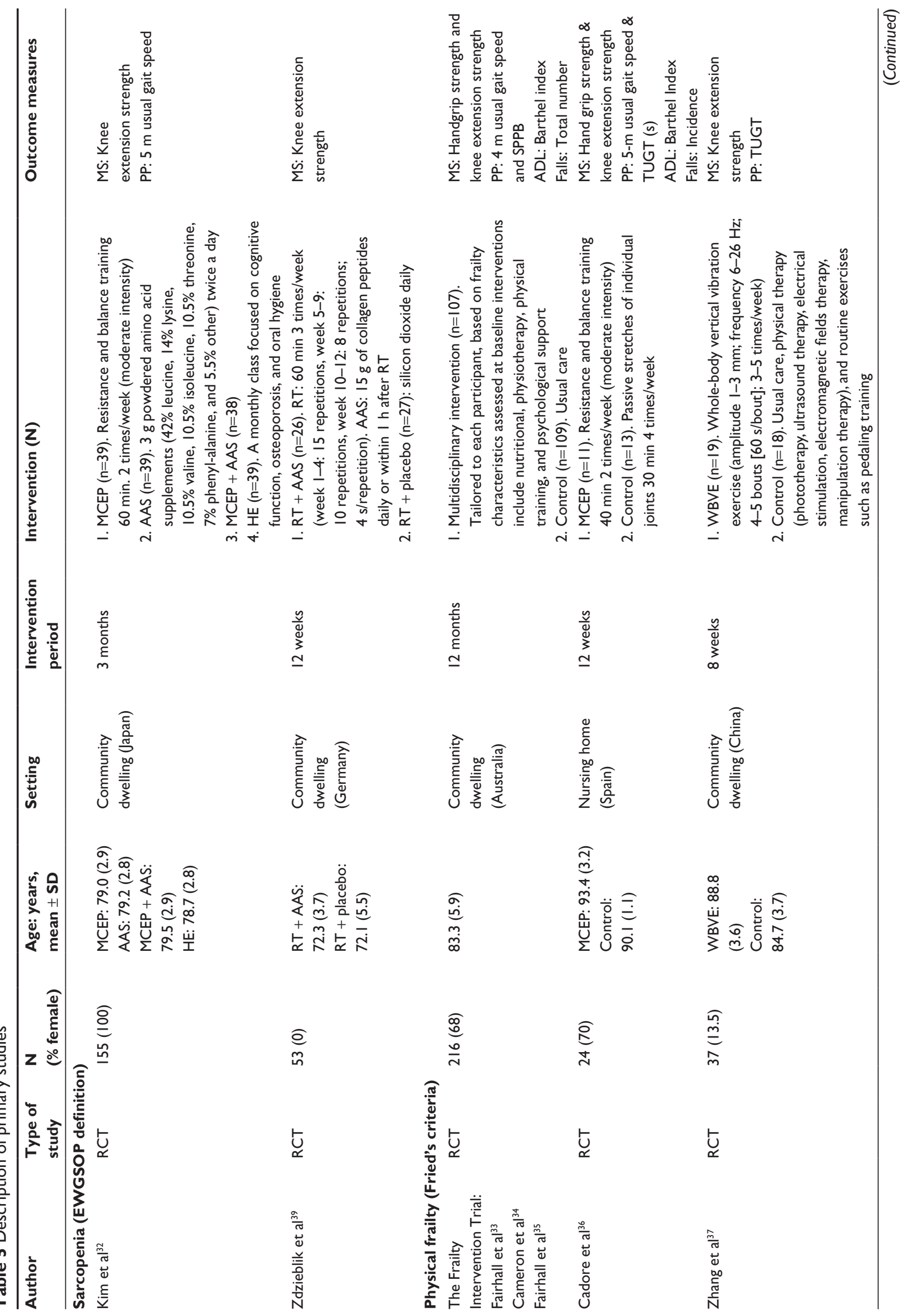




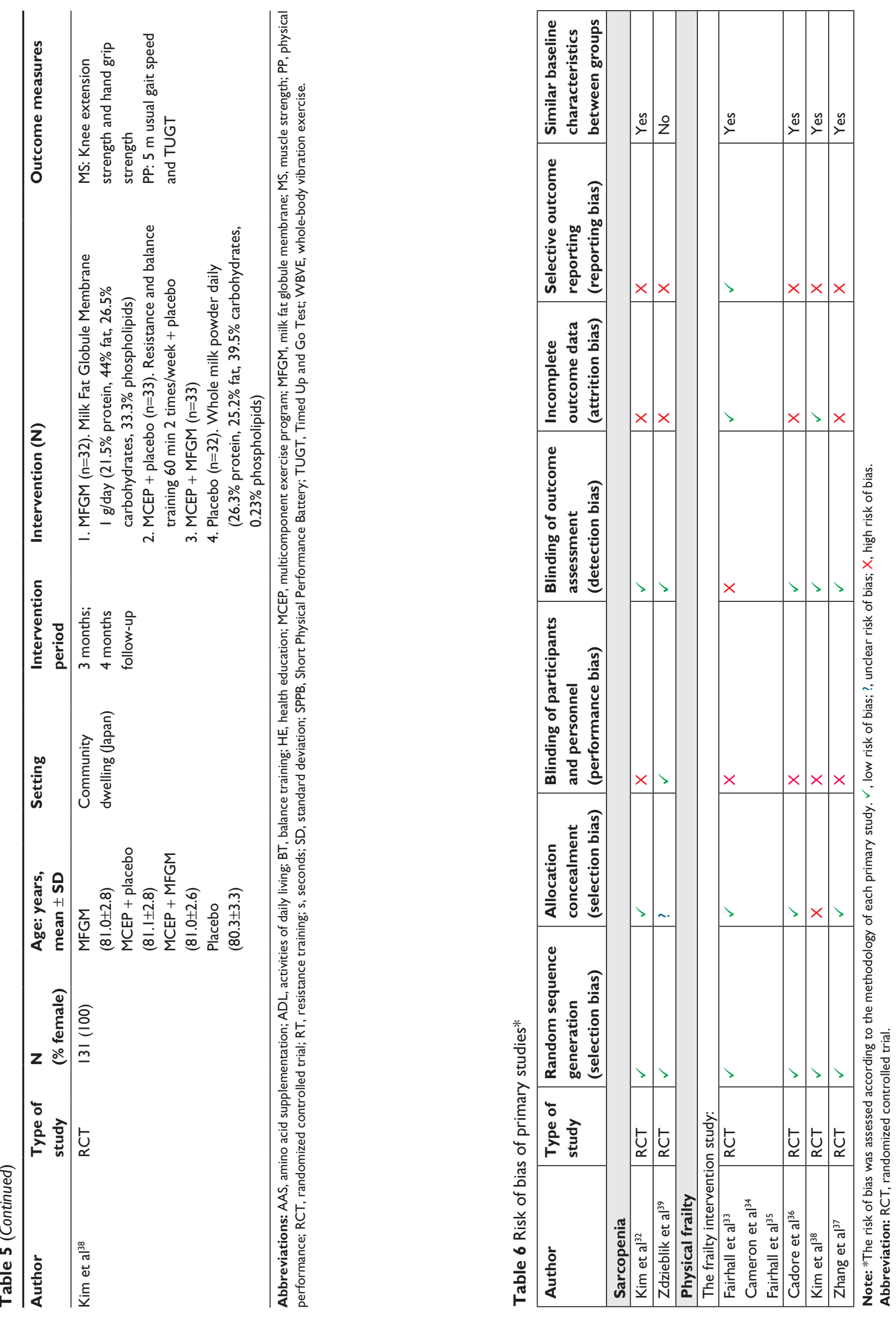



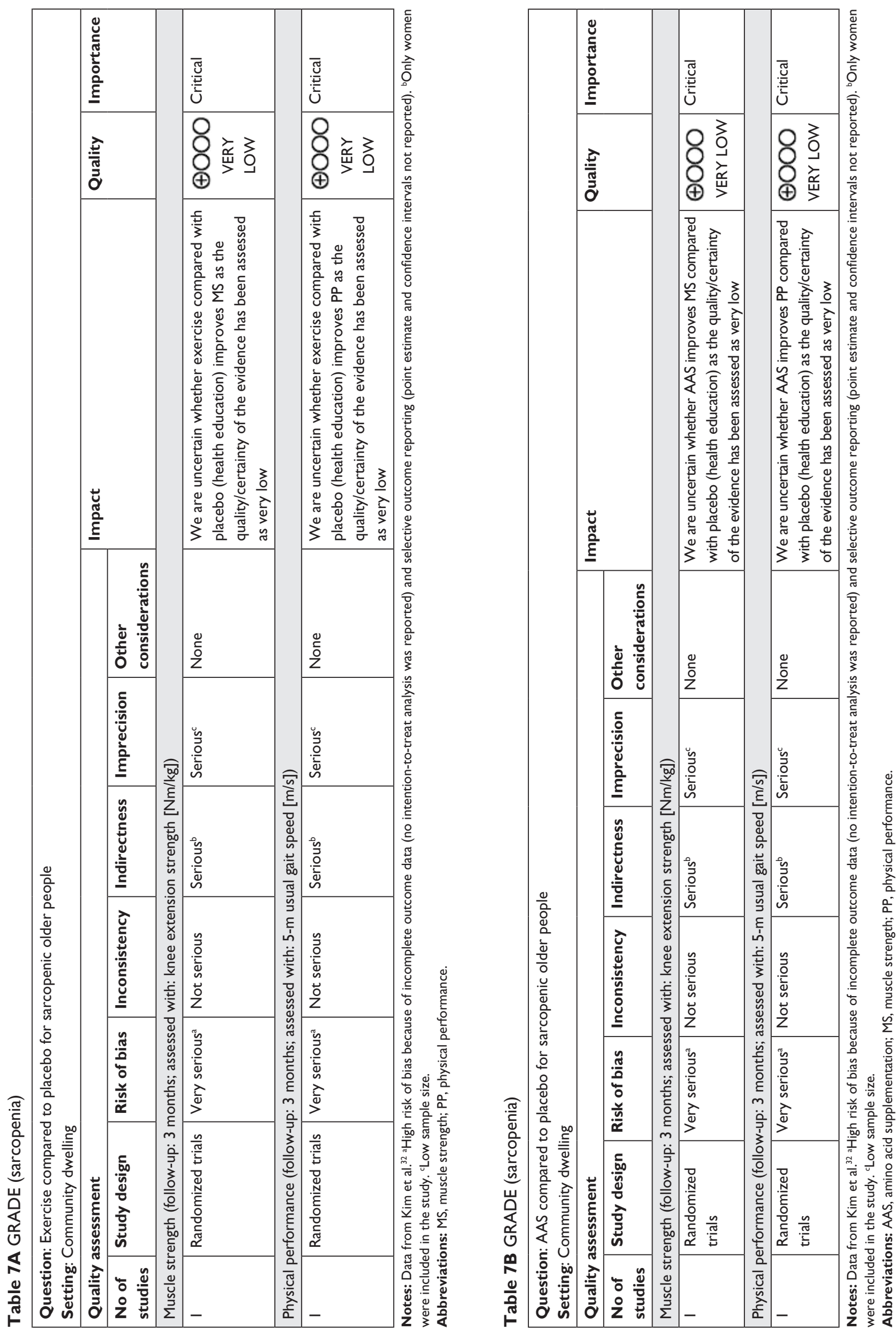

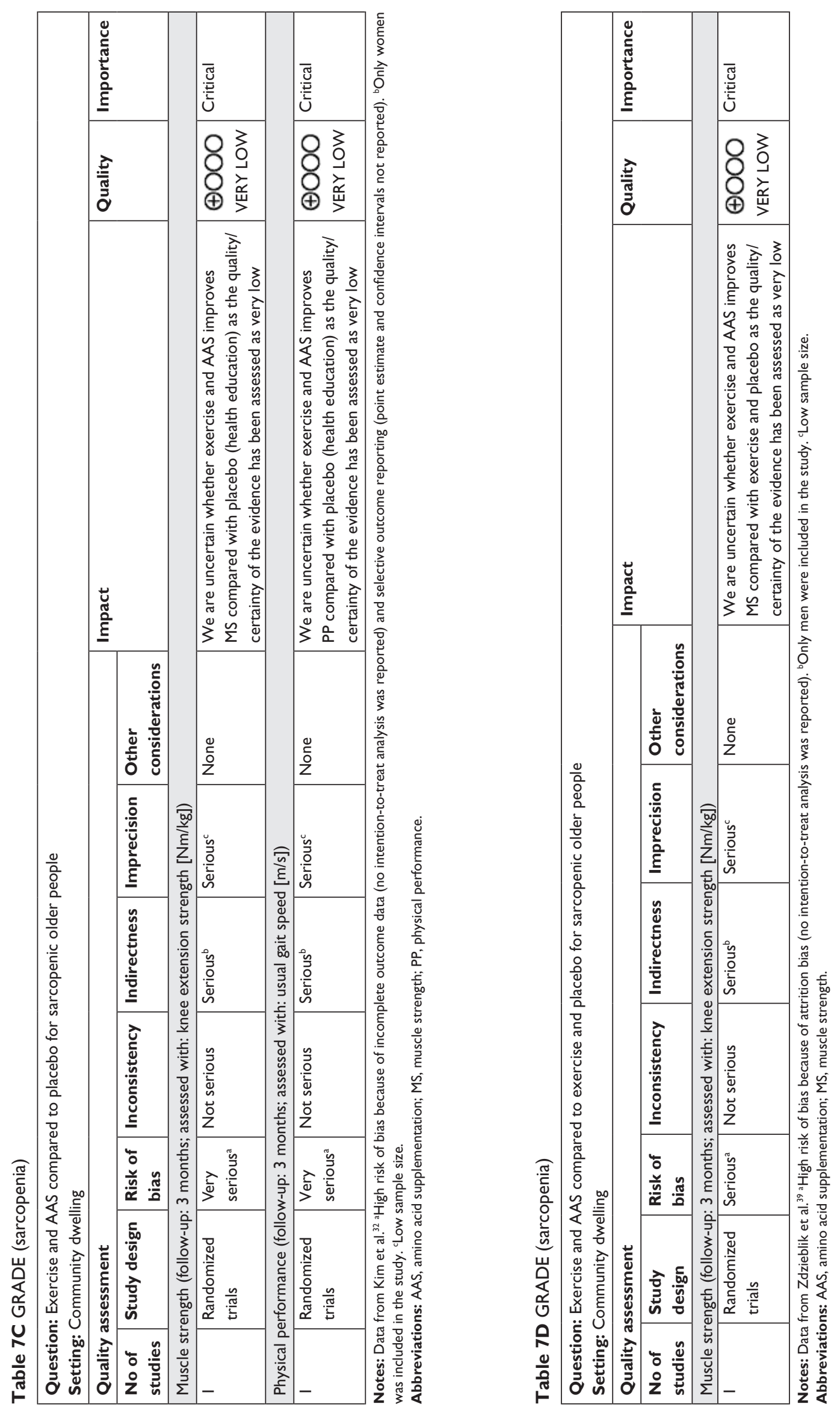


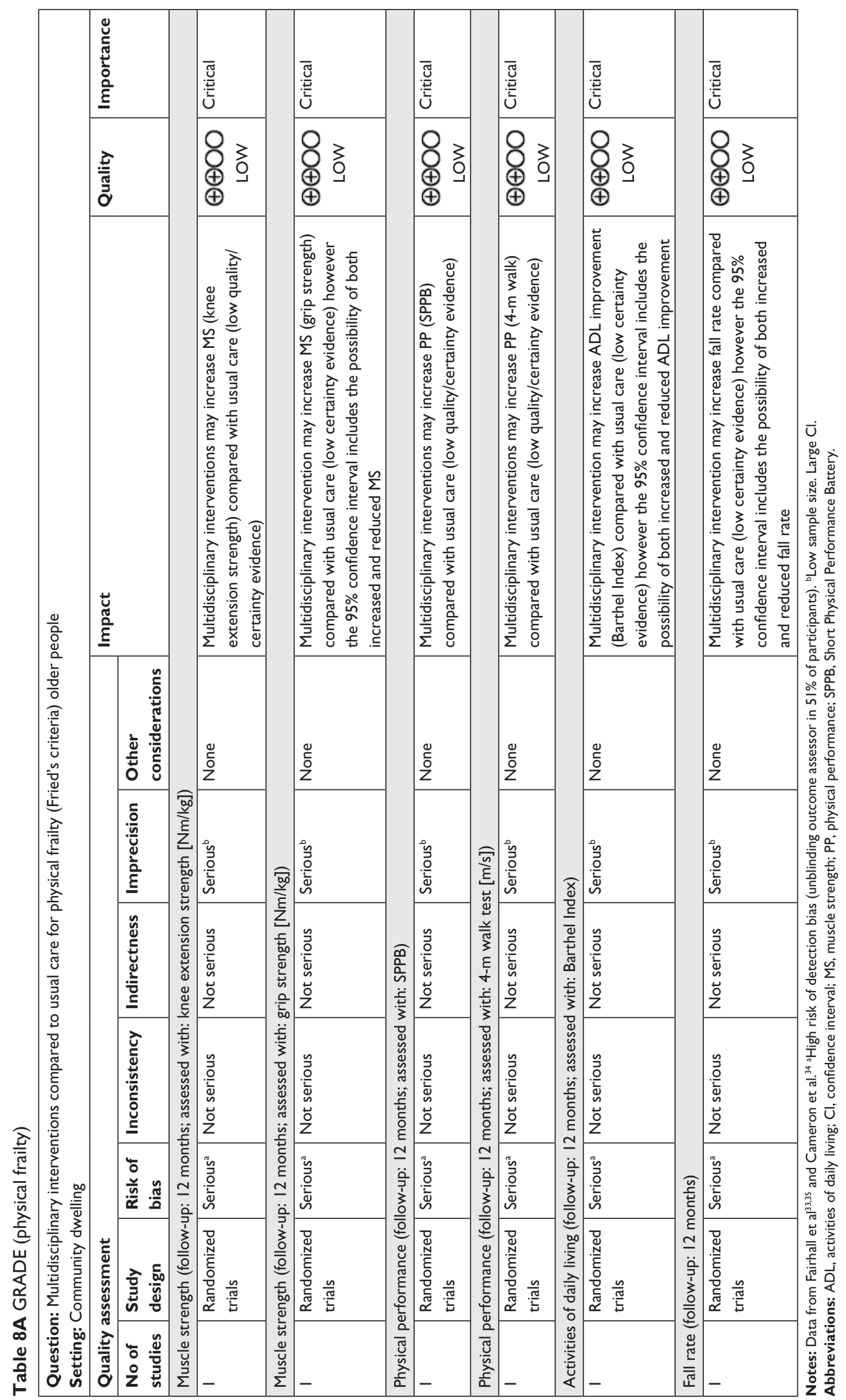



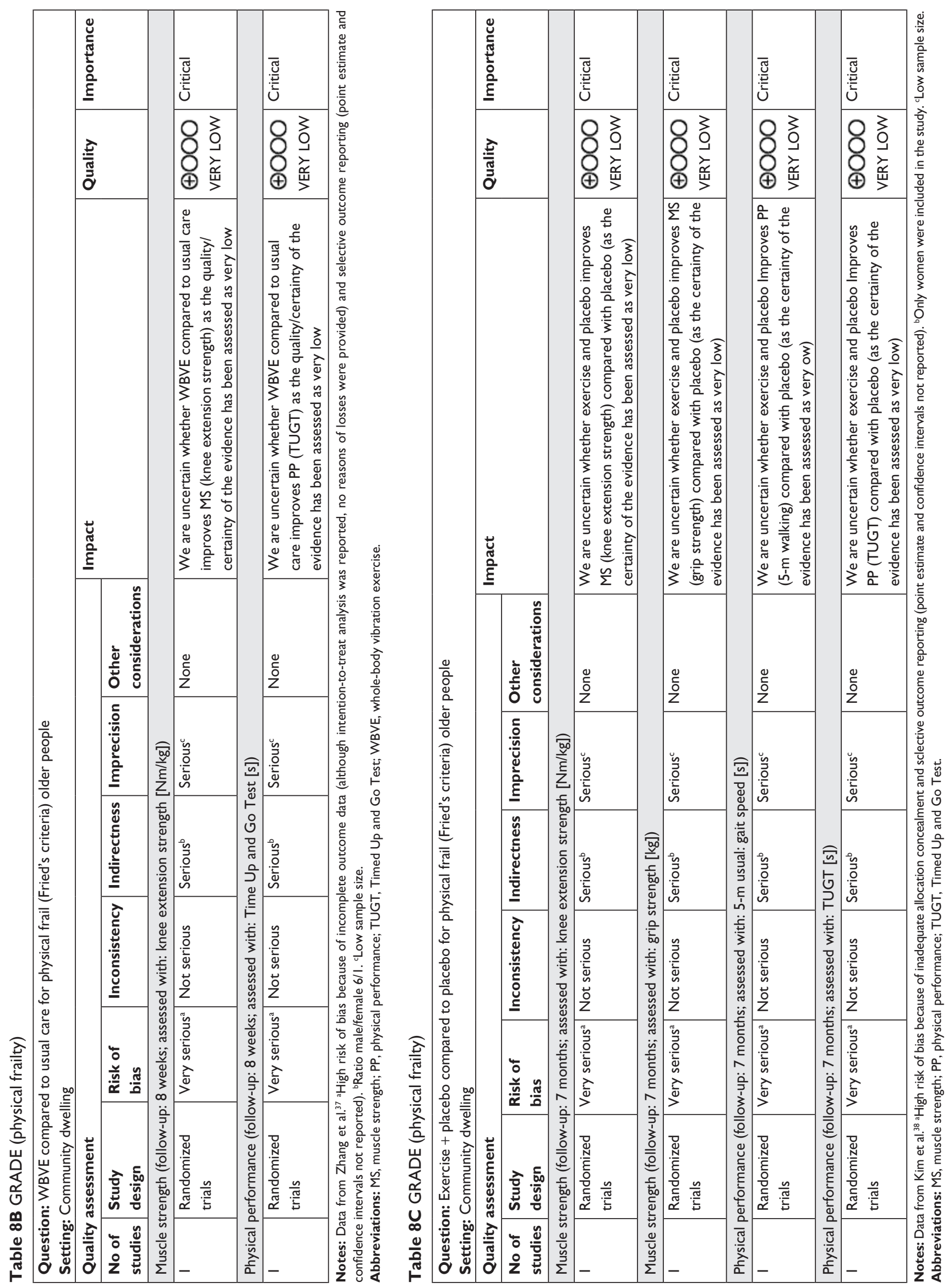


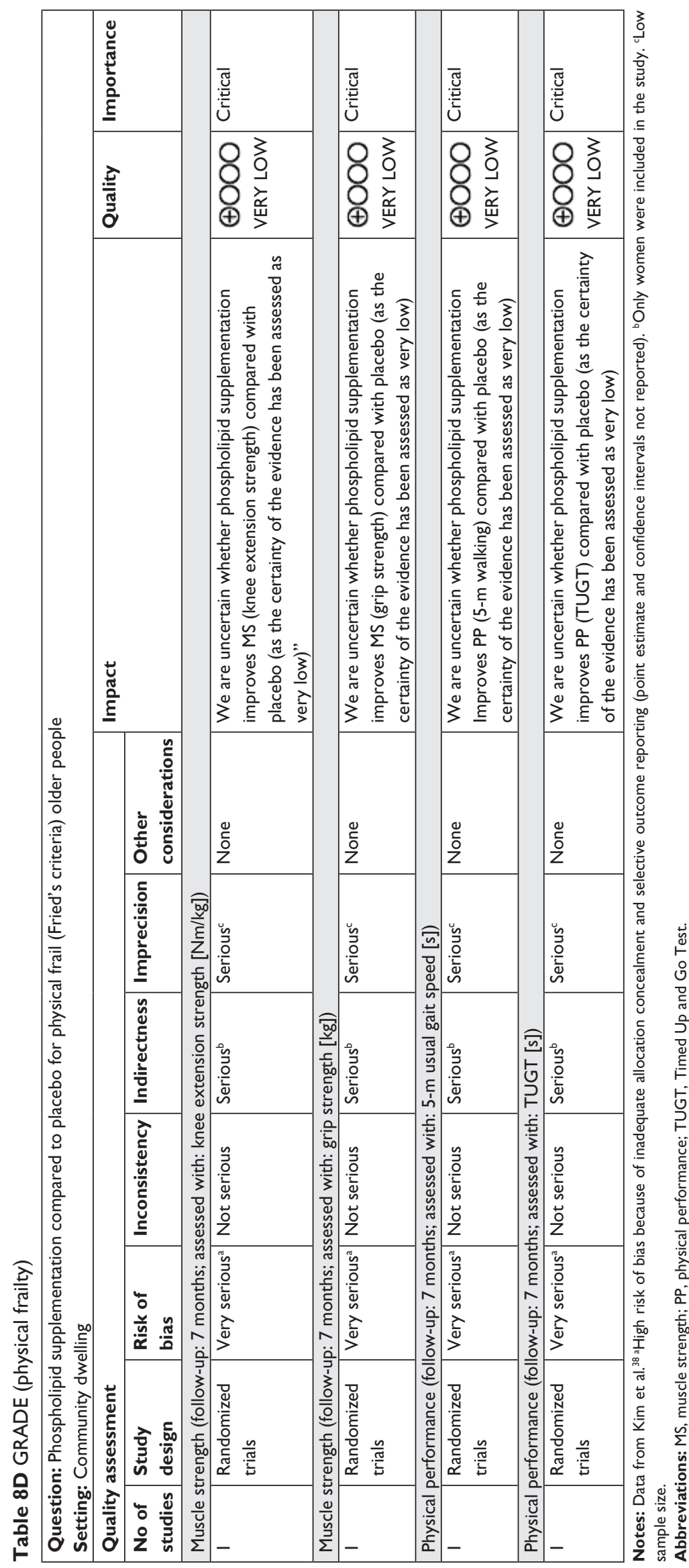




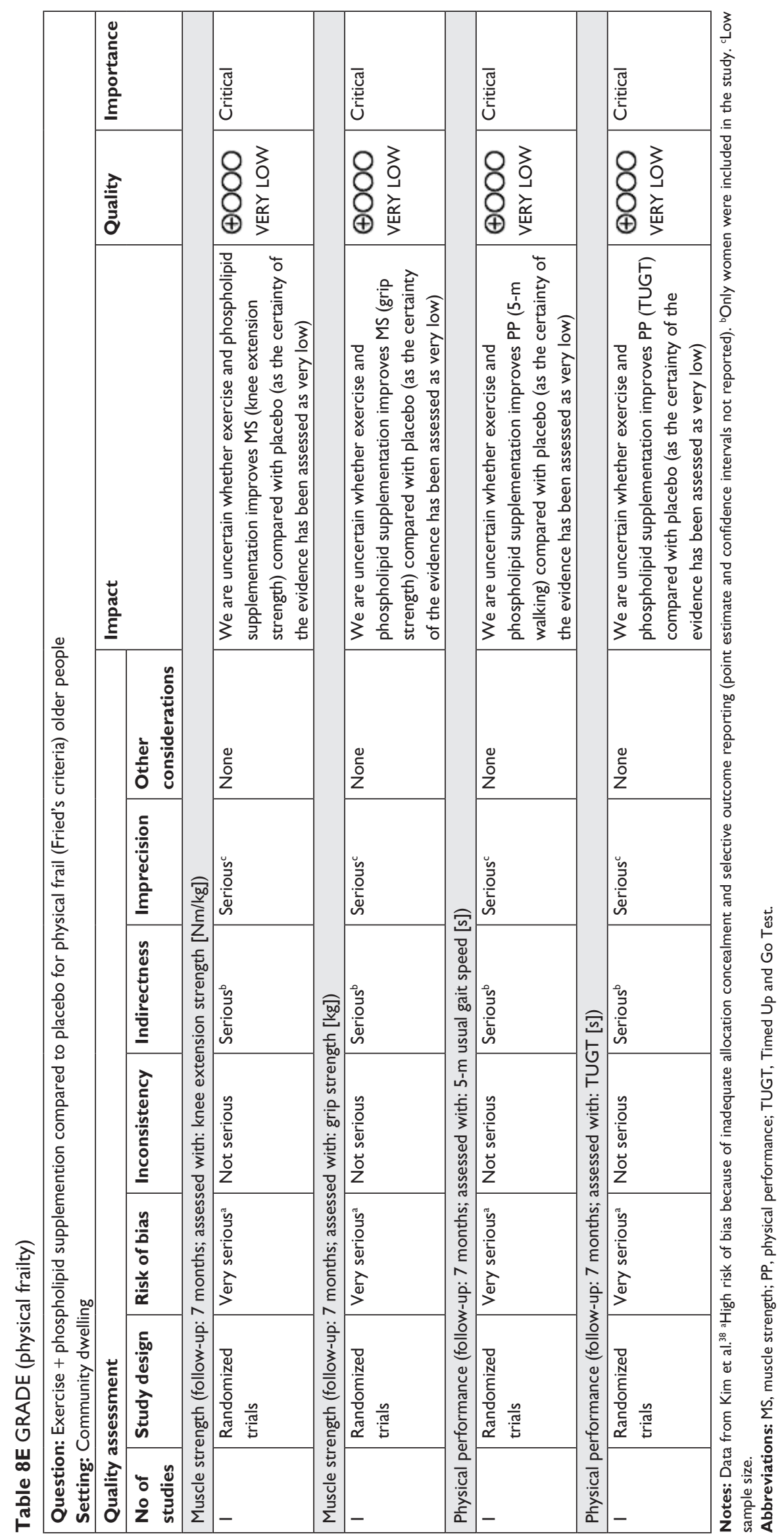




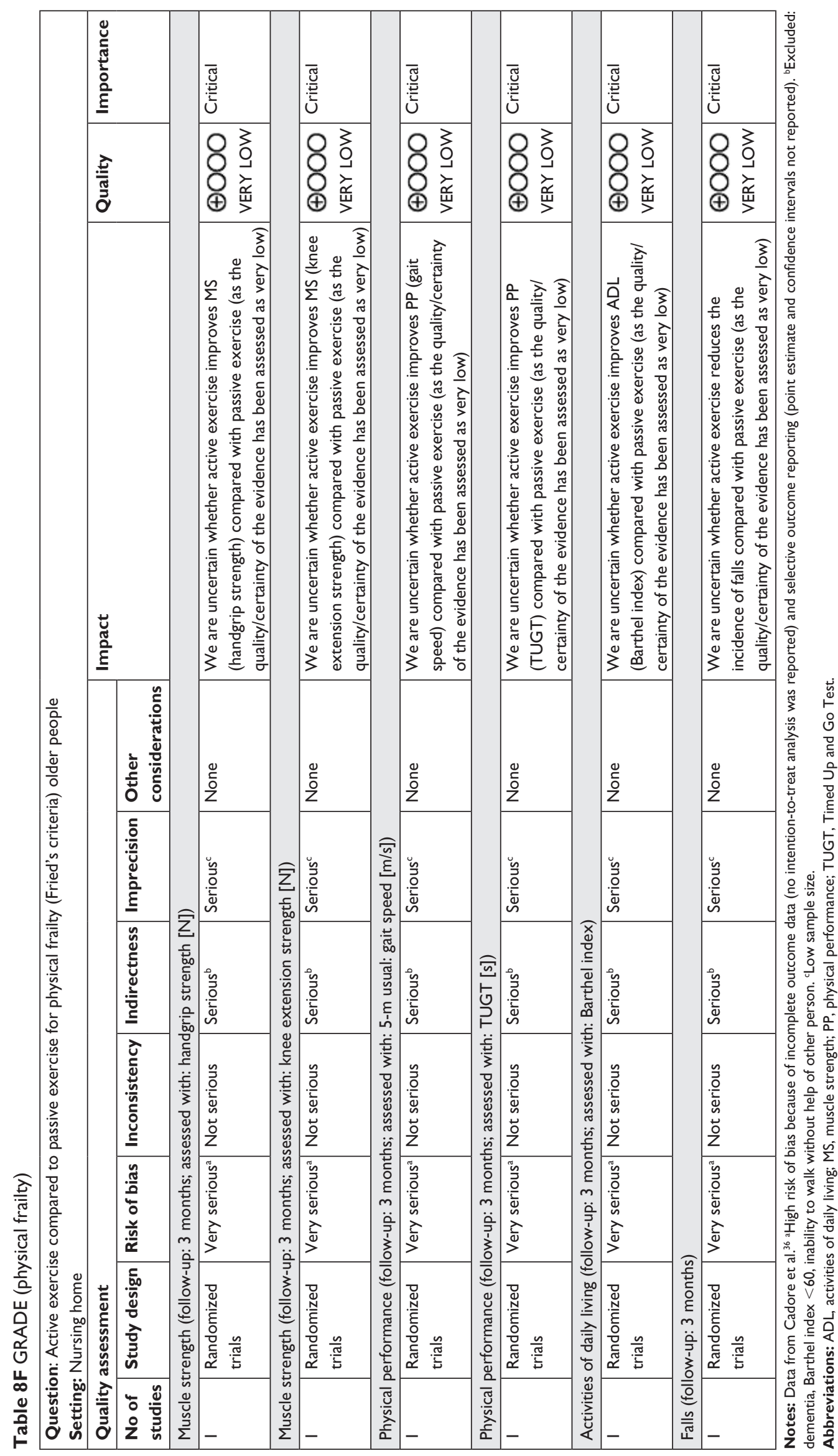




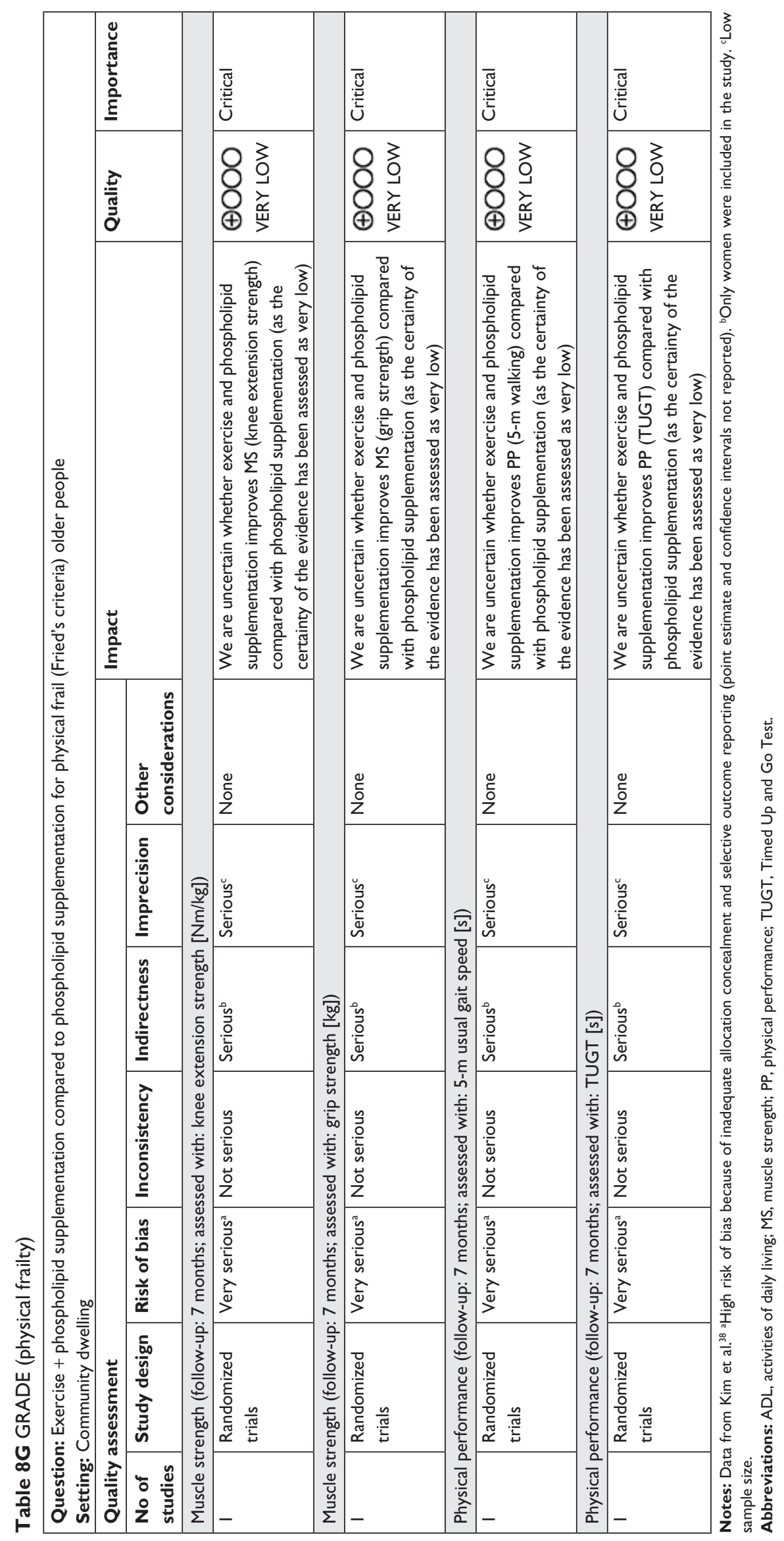


physical therapies and routine exercises, in 44 frail older Chinese subjects (mean age $\pm \mathrm{SD}=85.3 \pm 3.6$ years) during 8 weeks. Both the groups showed an improvement in MS (bilateral knee extension strength) by $52.31 \%$ versus $35.18 \%$ on the right leg and $61.78 \%$ versus $25.62 \%$ on the left leg in the intervention group versus control group, respectively. Moreover, PP (Timed Up and Go Test [TUGT]) also improved in both the groups: $-19.13 \mathrm{~s}$ in the intervention group versus $-7.37 \mathrm{~s}$ in the control group. These differences were statistically significant between groups $(P<0.05)$. However, further studies with larger sample sizes, longer study period, and follow-up period are needed to confirm these results.

The risk of bias according to methodological issues was low except for performance, attrition, and reporting bias (Table 6). In general, the quality or certainty of the evidence has been assessed as very low (Table $8 \mathrm{~B}$ ) for the critical outcomes.

\section{Evidence on exercise plus nutritional supplementation in physically frail community- dwelling older people}

One $\mathrm{RCT}^{38}$ evaluated the combined and separate effects of a MCEP and supplementation with milk fat globule membrane (MFGM) in 131 Japanese women aged $>75$ years during 3 months of intervention and 4 months of additional follow-up. The outcomes assessed were MS (handgrip strength and knee extension strength) and PP (5-m usual gait speed and TUGT). After 3-month intervention, there were no significant differences between groups in MS improvement. PP assessed by 5-m usual gait speed improved in the MCEP + MFGM group (0.1 s) compared with the MFGM group (0.02 s, $P=0.005)$. TUGT also improved with the MCEP + MFGM group (1.65 s) and the MCEP + placebo group (2.02 s) compared to MFGM (0.24 s) and placebo group $(0.44 \mathrm{~s}, P<0.001)$. However, an analysis of the effects of the intervention revealed that these effects were not maintained at 4 months of follow-up.

The risk of bias according to methodological issues was low except for selection, performance and reporting bias (Table 6). In general, the quality or certainty of the evidence has been assessed as very low (Table $8 \mathrm{C}-\mathrm{F}$ ) for the critical outcomes.

\section{Evidence on exercise in physically frail older people living in nursing homes}

Finally, a single $\mathrm{RCT}^{36}$ evaluated the efficacy of a MCEP (resistance, balance, and gait training) versus passive stretches in 24 nonagenarian institutionalized Spanish subjects during 12 weeks. The outcomes evaluated were MS (handgrip strength, knee extension strength), PP (5-m usual gait speed and TUGT), incidence of falls, and ADL status (BI). After the training period, there were significant differences between groups in MS $(P<0.01)$ : handgrip strength and knee extension strength improved by $11 \%$ and $20 \%$, respectively, in the intervention group versus a reduction of $17 \%$ and $14 \%$, respectively, in the control group. Moreover, the exercise group had a lower incidence of falls (from 0.77 to 0 ) and less ADL (BI score) deterioration than the control group with significant difference between them $(P<0.001)$. There were no significant differences in PP between groups.

The risk of bias according to methodological issues was low except for performance, attrition, and reporting bias (Table 6). In general, the quality or certainty of the evidence has been assessed as very low (Table 8G) for the critical outcomes.

\section{Summary of main results}

This overview was aimed to identify SRs of nonpharmacological interventions used to treat $\mathrm{PF}$ and sarcopenia in older patients from different care settings. From $10 \mathrm{SRs}^{22-31}$ meeting the inclusion criteria, data from 5 RCTs ( 7 articles) $)^{3-38}$ and one additional identified RCT, ${ }^{39}$ all published in the last 4 years were examined. In order to provide a summary for decision makers and guideline developers, the risk of bias (RoB) and the GRADE quality of evidence were assessed across outcomes for each individual study. The overall GRADE quality of evidence was judged to be low (Tables 7 and 8). In summary, this evidence points to some efficacy of physical exercise programs (that include resistance and balance training) in improving relevant outcomes. An additional relevant finding is the small number of articles that use standard definitions of frailty and sarcopenia.

\section{Discussion \\ Agreements and disagreements with other studies or reviews}

Some guidelines issued by official organizations have included recommendations on frailty. The Agency for Healthcare Research and Quality guideline ${ }^{43}$ recommends physical activity and monitoring diet and body weight as the main strategies to stabilize and control frailty. The British Geriatrics Society (BGS) ${ }^{44}$ recommends a holistic medical review based on the comprehensive geriatric assessment as gold standard to create an individualized care and support plan to manage frail people. The results of the FIT trial ${ }^{33-35}$ 
seem to support this recommendation, as it showed significant improvement on MS and PP (SPPB, gait speed) with a multidisciplinary intervention based on the assessment of deficiencies versus usual care. In addition, the $\mathrm{BGS}^{44}$ recognizes that exercise, in particular strength and balance training, improves both mobility and functional ability. However, the optimal exercise regimen to minimize frailty and sarcopenia remains uncertain. Moreover, the BGS indicates that nutritional interventions also need to be considered, although evidence to support this remains limited. Nutrition recommendations currently include optimizing protein intake and correcting vitamin D insufficiency. The European Society for Clinical Nutrition and Metabolism $(\mathrm{ESPEN})^{40}$ recommends that the diet should provide at least $1.0-1.2 \mathrm{~g}$ protein $/ \mathrm{kg}$ body weight/day and up to $1.2-1.5 \mathrm{~g}$ protein/kg body weight/day for malnourished/at risk of malnutrition older people, but this recommendation is based on data coming from longitudinal epidemiological studies, not on intervention trials. Higher intake of proteins is recommended for individuals with severe illness or injury. Daily physical activity or exercise (RT and aerobic exercise) should be undertaken by all older people, for as long as possible. These recommendations are in line with the results of the study by Kim et al in $2012^{32}$ included in this overview: an improvement in MS and PP (measured by GS) was achieved with the combination of exercise and AAS. However, in the study by Kim et al in $2015,{ }^{38}$ based on nutritional supplementation with phospholipids, an improvement only on PP was shown.

Although MS and PP are relevant intermediate outcomes, ${ }^{41}$ the studies included in this overview did not show improvements on hard outcomes, such as reduction in the incidence of falls or improved basic ADLs, with the exception of the only study performed in a very old population living in a nursing home. ${ }^{36}$ In this study, exercise significantly reduced the incidence of falls and attenuated ADL functional loss. Current guidelines of frailty do not consider these outcomes.

The majority of the populations included in the studies selected in this overview are Asian (from China and Japan), except for the FIT $^{33-35}$ study (Australian) and the study in nursing homes ${ }^{36}$ (Spanish). This is important because the results and conclusion from these trials may not be fully extrapolated to other populations and in other health care settings.

\section{Strengths and weaknesses of the study}

This study has several strengths compared with previously published studies, namely: 1) The authors conducted comprehensive searches in four electronic databases to ensure all published trials were identified. The search terms for this overview of SRs were intentionally broad to capture all studies, and this led to $>9,000$ abstracts. They used a multidisciplinary review group of authors with experience in conducting SRs to independently examine and select studies. 2) This is the first overview of SRs fully designed to gather the evidence of nonpharmacological interventions on specific populations defined by validated definitions of PF and sarcopenia; hence, the populations considered in this review are relatively homogeneous. An issue raised in previous SRs was the heterogeneous populations defined by very different and nonstandardized criteria, both for sarcopenia and frailty. 3) The interventions considered are deliverable in clinical practice. 4) The outcome measures considered in this study were pre-specified by a panel of experts and use validated and reproducible measures. Variability in outcome measures is limiting research in this area. ${ }^{42} 5$ ) The strength of evidence is evaluated according to the GRADE system.

On the other hand, this review has several limitations. First, the potential nondetection/nondiscovery of primary studies that were not found in any of the SRs. However, the methodology that is used has been previously used to gather evidence on other nonpharmacological approaches to common geriatric syndromes ${ }^{45-52}$ and is well described in medical research. ${ }^{18}$ Second, the arbitrary cut-off age of 65 years may limit the applicability of the evidence from the present overview of SRs in patients aged $<65$ years. Moreover, institutionalized patients are not well represented, and there are no data on hospitalized patients. Third, the studies included were heterogeneous in terms of interventions, with short intervention periods of 3 months in the majority of trials and scanty data on longer follow-up outcomes. The number of studies included and sample sizes were small, and as a result, meta-analysis was not possible.

\section{Conclusion General conclusion}

This overview of SR highlights the importance of exercise interventions with or without nutritional supplementation to improve PP (TUGT, GS) in community-dwelling patients aged $>65$ years with PF and sarcopenia. MS was improved with multidisciplinary and exercise interventions in this population. However, more trials with precise definitions of sarcopenia and PF with standardized outcome measures are clearly needed, especially in nutrition intervention studies.

\section{Implications for practice}

Sarcopenia and frailty are associated with multiple adverse events in older patients; hence, they warrant intervention. 
This overview suggests that resistance and balance exercise may be the first treatment step, with a possible effect of nutritional supplementation added to exercise to improve outcomes. Exercise and nutritional interventions seem to be safe and are recommended from a public health point of view in older populations, both healthy or with a wide range of co-morbid problems. Therefore, there seem to be no clear reasons to avoid these interventions in frail or sarcopenic patients. However, expected impact on outcomes needs to be interpreted with caution due to methodological limitations in the small number of trials available and the risk of bias in several domains.

\section{Implications of the research}

This overview of SRs emphasizes the need for well-designed, large-scale RCTs with validated definitions of PF and sarcopenia, and standardized outcomes before conclusions can be drawn on its effectiveness.

\section{Acknowledgments}

The authors thank the following panel members who participated in the Delphi process to identify relevant outcomes: Hubert Blain, Andrea Corsonello, Giuseppina Dell'aquila, Adalsteinn Gudmundsson, Gunnar Akner, Mirko Petrovic, Regina Roller-Wirnsberger, Fabio Salvi, and Fabiana Trotta. The research leading to these results has been funded by the European Union Seventh Framework Programme (FP7/2007-2013) under grant agreement No 305930 (SENATOR).

\section{Disclosure}

The authors report no conflicts of interest in this work.

\section{References}

1. Boers M, Cruz-Jentoft AJ. A new concept of health can improve the definition of frailty. Calcif Tissue Int. 2015;97(5):429-431.

2. Morley JE, Vellas B, van Kan GA, et al. Frailty consensus: a call to action. J Am Med Dir Assoc. 2013;14(6):392-397.

3. Michel JP, Cruz-Jentoft AJ, Cederholm T. Frailty, exercise and nutrition. Clin Geriatr Med. 2015;31(3):375-387.

4. Rockwood K, Bergman H. FRAILTY: a report from the 3(rd) Joint Workshop of IAGG/WHO/SFGG, Athens, January 2012. Can Geriatr J. 2012;15(2):31-36.

5. Fried LP, Tangen CM, Walston J, et al; Cardiovascular Health Study Collaborative Research Group. Frailty in older adults: evidence for a phenotype. J Gerontol A Biol Sci Med Sci. 2001;56(3):M146-M156.

6. Mitnitski AB, Graham JE, Mogilner AJ, Rockwood K. Frailty, fitness and late-life mortality in relation to chronological and biological age. BMC Geriatr. 2002;2:1.

7. Buta BJ, Walston JD, Godino JG, et al. Frailty assessment instruments: systematic characterization of the uses and contexts of highly-cited instruments. Ageing Res Rev. 2016;26:53-61.

8. Cesari M, Gambassi G, Van Kan GA, Vellas B. The frailty phenotype and the frailty index: different instruments for different purposes. Age Ageing. 2014;43(1):10-12.
9. Cruz-Jentoft AJ, Baeyens JP, Bauer JM, et al. Sarcopenia: European consensus on definition and diagnosis: report of the European Working Group on Sarcopenia in Older People. Age Ageing. 2010;39(4):412-423.

10. Landi F, Calvani R, Cesari M, et al. Sarcopenia as the biological substrate of physical frailty. Clin Geriatr Med. 2015;31(3):367-374.

11. Reijnierse EM, Trappenburg MC, Blauw GJ, et al. Common ground? The concordance of sarcopenia and frailty definitions. J Am Med Dir Assoc. 2016;17(4):371.e7-371.e12.

12. Kojima G. Frailty as a predictor of future falls among communitydwelling older people: a systematic review and meta-analysis. J Am Med Dir Assoc. 2015;16:1027-1033.

13. Gale CR, Cooper C, Sayer AA. Prevalence of frailty and disability: findings from the English Longitudinal Study of Ageing. Age Ageing. 2015; 44(1):162-165.

14. Kojima G. Frailty as a predictor of hospitalisation among communitydwelling older people: a systematic review and meta-analysis. $J$ Epidemiol Community Health. 2016;70(7):722-729.

15. Chang S-F, Lin P-L. Frail phenotype and mortality prediction: a systematic review and meta-analysis of prospective cohort studies. Int $J$ Nurs Stud. 2015;52(8):1362-1374.

16. Brown JC, Harhay MO, Harhay MN. Sarcopenia and mortality among a population-based sample of community-dwelling older adults. J Cachexia Sarcopenia Muscle. 2016;7(3):290-298.

17. Landi F, Calvani R, Tosato M, et al. Impact of physical function impairment and multimorbidity on mortality among community-living older persons with sarcopaenia: results from the ilSIRENTE prospective cohort study. BMJ Open. 2016;6(7):e008281.

18. Abraha I, Cruz-Jentoft A, Soiza RL, O’Mahony D, Cherubini A. Evidence of and recommendations for non-pharmacological interventions for common geriatric conditions: the SENATOR-ONTOP systematic review protocol. BMJ Open. 2015;5(1):e007488.

19. Schünemann H, Brozek J, Guyatt G, Oxman A, editors. GRADE Handbook for Grading Quality of Evidence and Strength of Recommendations. The GRADE Working Group [updated October 2013]; 2013. Available from: www.guideline development.org/handbook. Accessed May 29, 2016.

20. Montori VM, Wilczynski NL, Morgan D, Haynes RB; Hedges Team. Optimal search strategies for retrieving systematic reviews from Medline: analytical survey. BMJ. 2005;330(7482):68.

21. Higgins JPT, Altman DG; on behalf of the Cochrane Statistical Methods Group and the Cochrane Bias Methods Group. Chapter 8: Assessing risk of bias in included studies. In: Higgins JPT, Green S, editors. Cochrane Handbook for Systematic Reviews of Interventions Version 5.1.0. The Cochrane Collaboration [updated March 2011]; 2011.

22. Cadore EL, Rodríguez-Mañas L, Sinclair A, Izquierdo M. Effects of different exercise interventions on risk of falls, gait ability, and balance in physically frail older adults: a systematic review. Rejuvenation Res. 2013;16(2):105-114.

23. Cruz-Jentoft AJ, Landi F, Schneider SM, et al. Prevalence of and interventions for sarcopenia in ageing adults: a systematic review. Age Ageing. 2014;43(6):748-759.

24. Finger D, Goltz FR, Umpierre D, Meyer E, Rosa LH, Schneider CD. Effects of protein supplementation in older adults undergoing resistance training: a systematic review and meta-analysis. Sport Med. 2015; 45(2):245-255.

25. Komar B, Schwingshackl L, Hoffmann G. Effects of leucine-rich protein supplements on anthropometric parameter and muscle strength in the elderly: a systematic review and meta-analysis. J Nutr Health Aging. 2015;19(4):437-446.

26. Malafarina V, Uriz-Otano F, Iniesta R, Gil-Guerrero L. Effectiveness of nutritional supplementation on muscle mass in treatment of sarcopenia in old age: a systematic review. J Am Med Dir Assoc. 2013;14(1):10-17.

27. Gine-Garriga M, Roque-Figuls M, Coll-Planas L, Sitja-Rabert M, Salva A. Physical exercise interventions for improving performancebased measures of physical function in community-dwelling, frail older adults: a systematic review and meta-analysis. Arch Phys Med Rehabil. 2014;95(4):753.e3-769.e3. 
28. de Labra C, Guimaraes-Pinheiro C, Maseda A, Lorenzo T, Millán-Calenti JC. Effects of physical exercise interventions in frail older adults: a systematic review of randomized controlled trials. BMC Geriatr. 2015; 15:154.

29. Orr R. The effect of whole body vibration exposure on balance and functional mobility in older adults: a systematic review and metaanalysis. Maturitas. 2015;80(4):342-458.

30. Plummer P, Zukowski LA, Giuliani C, Hall AM, Zurakowski D. Effects of physical exercise interventions on gait-related dual-task interference in older adults: a systematic review and meta-analysis. Gerontology. 2015;62(1):94-117.

31. Zanotto T, Bergamin M, Roman F, et al. Effect of exercise on dual-task and balance on elderly in multiple disease conditions. Curr Aging Sci. 2014;7(2):115-136.

32. Kim HK, Suzuki T, Saito K, et al. Effects of exercise and amino acid supplementation on body composition and physical function in community-dwelling elderly Japanese sarcopenic women: a randomized controlled trial. J Am Geriatr Soc. 2012;60(1):16-23.

33. Fairhall N, Sherrington C, Kurrle SE, Lord SR, Lockwood K, Cameron ID. Effect of a multifactorial interdisciplinary intervention on mobility-related disability in frail older people: randomised controlled trial. BMC Med. 2012;10:120.

34. Cameron ID, Fairhall N, Langron C, et al. A multifactorial interdisciplinary intervention reduces frailty in older people: randomized trial. BMC Med. 2013;11:65.

35. Fairhall N, Sherrington C, Lord SR, et al. Effect of a multifactorial, interdisciplinary intervention on risk factors for falls and fall rate in frail older people: a randomised controlled trial. Age Ageing. 2014;43(5):616-622.

36. Cadore EL, Casas-Herrero A, Zambom-Ferraresi F, et al. Multicomponent exercises including muscle power training enhance muscle mass, power output, and functional outcomes in institutionalized frail nonagenarians. Age (Dordr). 2014;36(2):773-785.

37. Zhang L, Weng C, Liu M, Wang Q, Liu L, He Y. Effect of whole-body vibration exercise on mobility, balance ability and general health status in frail elderly patients: a pilot randomized controlled trial. Clin Rehabil. 2014;28(1):59-68.

38. Kim H, Suzuki T, Kim M, et al. Effects of exercise and milk fat globule membrane (MFGM) supplementation on body composition, physical function, and hematological parameters in community-dwelling frail Japanese women: a randomized double blind, placebo-controlled, follow-up trial. PLoS One. 2015;10(2):e0116256.

39. Zdzieblik D, Oesser S, Baumstark MW, Gollhofer A, König D. Collagen peptide supplementation in combination with resistance training improves body composition and increases muscle strength in elderly sarcopenic men: a randomised controlled trial. Br J Nutr. 2015;114(8):1237-1245.

40. Deutz NE, Bauer JM, Barazzoni R, et al. Protein intake and exercise for optimal muscle function with aging: recommendations from the ESPEN Expert Group. Clin Nutr. 2014;33(6):929-936.

41. Reginster JY, Cooper C, Rizzoli R, et al. Recommendations for the conduct of clinical trials for drugs to treat or prevent sarcopenia. Aging Clin Exp Res. 2016;28(1):47-58.
42. Peña Ordóñez GG, Bustamante Montes LP, Ramírez Duran N, Sánchez Castellano C, Cruz-Jentoft AJ. Populations and outcome measures used in ongoing research in sarcopenia. Aging Clin Exp Res. Epub 2016 Aug 1.

43. National Guideline Clearinghouse (NGC). Guideline summary: frailty in elderly people. In: National Guideline Clearinghouse (NGC) [Web site]. Rockville (MD): Agency for Healthcare Research and Quality (AHRQ); Jan 1, 2013. Available from: https://www.guideline.gov/ summaries/summary/47484. Accessed June 24, 2016.

44. Fit for Frailty - consensus best practice guidance for the care of older people living in community and outpatient settings - a report from the British Geriatrics Society; 2014. Available from: http://www.bgs.org. uk/campaigns/fff/fff_full.pdf. Accessed July 17, 2016.

45. Lozano-Montoya I, Vélez-Díaz-Pallarés M, Abraha I, et al. Nonpharmacologic interventions to prevent pressure ulcers in older patients: an overview of systematic reviews (the Software ENgine for the Assessment and optimization of drug and non-drug Therapy in Older peRsons [SENATOR] Definition of Optimal Evidence-Based Non-drug Therapies in Older People [ONTOP] Series). J Am Med Dir Assoc. 2016; 17(4):370.e1-370.e10.

46. Vélez-Díaz-Pallarés M, Lozano-Montoya I, Abraha I, et al. Nonpharmacologic interventions to heal pressure ulcers in older patients: an overview of systematic reviews (the SENATOR-ONTOP Series). J Am Med Dir Assoc. 2015;16(6):448-469.

47. Vélez-Díaz-Pallarés M, Lozano-Montoya I, Correa-Pérez A, et al. Nonpharmacological interventions to prevent or treat pressure ulcers in older patients: Clinical practice recommendations. The SENATOR-ONTOP series. Eur Geriatr Med. 2016;7(2):142-148.

48. Abraha I, Rimland JM, Trotta F, et al. Non-pharmacological interventions to prevent or treat delirium in older patients: clinical practice recommendations the SENATOR-ONTOP series. J Nutr Health Aging. 2016; 20(9):927-936.

49. Abraha I, Trotta F, Rimland JM, et al. Efficacy of non-pharmacological interventions to prevent and treat delirium in older patients: a systematic overview. The SENATOR project ONTOP Series. PLoS One. 2015; 10(6): $\mathrm{e} 0123090$.

50. Rimland JM, Abraha I, Dell'Aquila G, et al. Effectiveness of nonpharmacological interventions to prevent falls in older people: a systematic overview. The SENATOR Project ONTOP Series. PLoS One. 2016;11(8):e0161579.

51. Rimland JM, Dell'Aquila G, O'Mahony D, et al. Meta-analysis of multifactorial interventions to prevent falls of older adults in care facilities. J Am Geriatr Soc. 2015;63(9):1972-1973.

52. Abraha I, Rimland JM, Trotta F, et al. Systematic review of systematic reviews of non-pharmacological interventions to treat behavioural disturbances in older patients with dementia. The SENATOR-OnTop series. BMJ Open. 2017;7(3):e012759.
Clinical Interventions in Aging

\section{Publish your work in this journal}

Clinical Interventions in Aging is an international, peer-reviewed journal focusing on evidence-based reports on the value or lack thereof of treatments intended to prevent or delay the onset of maladaptive correlates of aging in human beings. This journal is indexed on PubMed Central, MedLine,
Dovepress

CAS, Scopus and the Elsevier Bibliographic databases. The manuscript management system is completely online and includes a very quick and fair peer-review system, which is all easy to use. Visit http://www.dovepress. com/testimonials.php to read real quotes from published authors. 